\title{
Peer Relationships, Learning Forums, And Work Outcomes: An Empirical Analysis
}

Gary Kleinman, (Email: Gk49593@cs.com), Fairleigh Dickinson University Philip Siegel, (E-mail: Philip.siegel@gte.net), Fairleigh Dickinson University

Claire Eckstein, Fairleigh Dickinson University

\begin{abstract}
The pace of organizational and environmental change seems to demand that such professional organizations as CPA firms become learning organizations in order to compete with other firms. The flattening or thinning out of traditional hierarchical structures within organizations argues that traditional mentoring and supervisory structures may be inadequate for fostering needed individual learning about (a) organizational goals and politics, and (b) personal learning about job context and skill development, thus the ability of individuals within CPA firms to master new skills may be impaired. One effect of the lack of such learning may be increased role stress, job burnout, loss of commitment to the organization, intention to leave, and diminished job satisfaction. Using a sample of 440 accounting professionals from major CPA firms in the southeastern, southwestern, and northeastern regions of the United States, this research studies the ability of peer developmental relationship functions foster the requisite personal and organizational learning, and also to directly and indirectly influence attitudinal outcomes. We further examine whether the impact of developmental peer relationships on attitudinal outcomes is mediated by personal and organizational learning.
\end{abstract}

A hierarchical regression-based test was used to evaluate our hypotheses. The results partially supported our expectations that such peer developmental relationship functions were significantly related to attitudinal outcomes, to elements of organizational learning, and to the skill development aspect of personal learning. Elements of organizational socialization, personal learning, and team-source learning were significantly related to attitudinal outcomes as well.

\section{Introduction}

Organizations of all types are facing increasingly turbulent economic environments, environments characterized by increasing global competition, rapid turnover of personnel, reduced levels of corporate hierarchy, and the need to rapidly integrate newly-hired personnel into the firm in order to assure that the new personnel can make contributions to the firm's success as quickly as possible (see Kleinman, Siegel and Eckstein, 2001). Therefore, organizations need information that will facilitate transforming themselves into learning organizations, thereby transmitting knowledge and desirable attitudes to firm personnel. The creation of learning forums is a method to assure such transmissions of attitudes and knowledge. This study examines the ability of peer relationships to serve as a learning forum (Kleinman et al., 2001; Senge, 1990).

We suggest that a Learning Forum describes an environment wherein acquisition of wisdom, knowledge, and skills is obtained through open discussions and participation of employees at all levels of the organization (e.g., Kleinman et al., 2001). We regard peer relationships as one potential type of learning forum in that it promotes the acquisition of knowledge, skills, and attitudes that may be positively or negatively related to organizational outcomes.

Readers with comments or questions are encouraged to contact the authors via email. 
Restructuring, downsizing, mergers and acquisitions are terms that have become increasingly familiar. All of these, as well as the need to reduce the number of levels of hierarchy within the firms, have an impact upon employees that is difficult to measure. Given the resultant, likely distrust between lower level employees and supervisors, employees probably rely more on their peers as sources of both emotional (attitudinal) and other learning. The nature and consequences of this learning have not been addressed fully elsewhere in the accounting literature but may have important consequences for firms.

CPA firms, like other firms, have not escaped the merger and restructuring manias and are similarly experiencing problems related to restructuring, technological advancement, and increased competition. To compete successfully in the 21 st century, CPA firms will have to transform themselves into learning organizations (Kleinman et al., 2001). A learning organization supports learning for all employees through its policies, practices and structure. The inability of individuals and groups to share information and communicate with one another, to reflect on actions and outcomes, to try new and varied methods, and to disseminate new learning may significantly impede a firm's ability to improve itself and remain competitive (Kaplan, Keinath and Walo, 2001).

This research examines whether peer-based learning forums can be instrumental in providing feelings of belonging and identification, thus creating a non-threatening environment in which confident employees gain knowledge, skills, competence, and an improved understanding of the CPA firm. If so, these developmental relationships would represent sources of individual learning that are crucial in fostering organizational learning (see Kleinman, Siegel and Eckstein, forthcoming 2002). As such, the findings of this study should aid firm management in understanding the impact of peer relationships on knowledge and attitude acquisition.

The remainder of this paper is organized as follows. The purpose and contribution of this study appears in Section I. Section II contains a review of the literature on peer relationships. The hypothesis tests are presented in Section III and the research design in Section IV. The results are presented in Section V and the conclusions in Section VI.

\section{Section I}

Purpose and Contributions of this Research

The conceptual model guiding this study is illustrated in Figure 1. This paper explores the ability of peer developmental relationships to serve as learning forums in a CPA firm. Specifically, this study examines the impact of peer developmental experiences on attitudinal outcomes of employees, including job satisfaction, organizational commitment, intentions to leave, role stress, job burnout and teamwork orientation. While several of these outcomes have been examined in terms of mentoring relationships within CPA firms (Dreher \& Ash, 1990; Fagenson, 1989; Kram, 1985; Scandura, 1992; Wilson \& Elman, 1990; Scandura and Viator, 1994), outcomes associated with peer relationships have received far less attention (Siegel, 2000; Siegel et al., 1998; Kaplan et al., 2001). This research assesses whether individual learning explains the relationship between developmental experiences and job related attitudes. Organizational socialization has been found to mediate the relationship between peer mentoring and work-induced stress (Siegel et al., 1998). To our knowledge, no other accounting research has explored the relationship between peer functions and job attitudes by identifying and testing significant mediators.

Accounting studies have failed to examine the contribution of varied developmental experiences to learning and outcomes (except for mentoring, cf Kleinman et al., 2001). In the aftermath of downsizing, potential mentors have been eliminated from CPA firms as these firms seek to cut costs by reducing the number of managerial layers within their firms. As hierarchical ranks are trimmed, there are fewer individuals with the skill and experience to perform role-modeling functions, and provide vocational and psychosocial support to the would-be mentees (Kleinman et al., 2001; Viator, 1999). Thus, traditional hierarchical mentors may not be able to provide coaching, insight, and guidance for protégés. Therefore, peer relationships may become a more significant factor in the employee's social network (Siegel, 2000). Investigating the impact of peer relationships could assist in determining optimal combinations of learning forums (sources). The synergistic effect of varied (e.g., mentoring and 

peer) forums would result in an increase in the desired outcomes of CPA firms. ${ }^{1}$

\section{Section II}

Literature Review: Peer Developmental Relationships

Kram (1985) indicated that peers in the work place might provide the opportunity for a developmental relationship between employees. Peers can provide some of the career and psychosocial functions experienced in mentoring relationships (Siegel, 2000; Kaplan et al., 2001; Allen, Maetzke \& Russell, 1994; Kram \& Isabella, 1985). Peer relationships provide a mutual-exchange mechanism that is less pronounced in a mentor relationship. Increased contact with peers provides opportunities to share perspectives about the CPA firm, as well as jobrelated and personal feedback (Siegel et al., 1998). The egalitarian nature of peer developmental relationships provides a forum wherein learning can thrive.

Kram and Hall (1995) suggested that peer relationships offer unique advantages to employees, as they could be both more accessible and enduring than most mentoring alliances. In a CPA environment of increasing uncertainty, peers share the challenge of trying to understand what is occurring within the firm, and can provide a unique form of support (Siegel et al., 1998; Kaplan et al., 2001).

Kram \& Isabella (1985) reported findings from interviews with 25 peer pairs that resulted in the identification of developmental benefits provided by peer relationships that parallel those provided by conventional mentoring relationships. The benefits from such relationships might include information sharing, career strategizing, job-related feedback, confirmation, emotional support and personal feedback.

Several types of peer relationships have been identified. An individual may have an information peer where the primary exchange is information sharing. Another individual may have a collegial peer in which the relationship also includes career strategizing, job-related feedback and friendship. Lastly, an individual may have a special peer, where the exchanges involve provision of emotional support, confirmation and personal feedback (Siegel, 2000). Kram and Isabella's study of peer relationships suggest that these types of relationships may offer unique developmental opportunities due to the mutuality of a two-way exchange of guidance and support. The absence of a hierarchical relationship may make it more critical to establish closer communication and collaboration.

A study by Allen, Maetzke \& Russell (1994) confirmed that peers provide psychosocial and career functions. Allen, McManus, Russell and Reiniger (1995) examined peer mentoring among 64 MBA students and the impact of the relationship upon 4 aspects of socialization (performance proficiency, politics, people, organizational goals and values) and work-related stress. They reported that peer mentors were able to provide more psychosocial functions than vocational functions. The researchers found psychosocial peer mentoring related to politics and performance proficiency aspects of socialization.

Allen et al. (1995) and Siegel (2000) reported that peer mentors were able to provide more guidance concerning day-to-day operations than traditional mentors who may not be able to supervise daily activities. These studies also found that vocational support was related to socialization (e.g., peer mentors provided important contacts and access to networks). The results supported the hypotheses for a mediation model in which peer mentoring was related to socialization and socialization, in turn, was related to work-related stress. No direct relationship was detected between peer mentoring and stress.

The studies above conceptualized and measured whether peer developmental relationships provided mentoring functions (psycho-social, role modeling, and vocational support). These studies argued that peer relationships and mentoring were fundamentally different in that peer relationships are characterized by both mutuality and two-way exchange. Using measures based on the concept of hierarchical mentoring to appraise the exchange in a peer developmental relationship fails to capture this mutuality. Ostroff \& Kozlowski (1993) investigated what

\footnotetext{
${ }^{1}$ See Kleinman and Palmon (2001) for a comprehensive discussion of the sociological, social psychological, and organization theory aspects of power, control, professionalism, role relations, and social relation stresses in CPA firms.
} 
types of information (role, task, group and organization) are provided to new organizational members ${ }^{2}$ from different sources such as: mentor, supervisor, co-worker (peers), observing others, trial and error, and policy handbooks. Results indicated that organizational newcomers who had mentors acquired more information about the organizational domain (organizational culture, politics and history) than non-mentored individuals did. Individuals without mentors used peers significantly more than individuals with mentors to obtain information specific to the job, work group and organization. Even individuals with mentors used peers as much, or more than, their mentors to obtain information.

The extant mentoring literature has failed to consider such contextual factors as other interpersonal relationships and developmental experiences (e.g., peer relationships). The research on peer relationships suggests that these relationships can also contribute to personal and professional growth. However, this research has been confined to examining the role of peer relationships with outcomes of socialization and stress (Allen et al., 1995; Siegel, 2000; Siegel et al., 1998). The importance of both learning organizations (Bennett \& O'Brien, 1994; Dodgson, 1993; Senge, 1990) and peer relationships (Clawson, 1996; Kram \& Hall, 1995) have been documented. Furthermore, the current turbulence (e.g., technological and competitiveness changes) in the business environment argues that there will be an increase in the importance of peer relationships (Kleinman et al., 2001). Based upon the foregoing, we conducted research to examine peer relations as learning forums. The results of our inquiry should serve to enhance our understanding in this area and assist managers in CPA firms in meeting their organizational objectives, and educators in understanding the importance of peer interaction in generating important attitudinal and knowledge outcomes.

\section{Section III}

Hypotheses

Based on the literature reviews and preliminary qualitative interviews, the research model shown in Figure 1 is proposed. The model suggests that learning, in the form of organizational socialization and personal learning, mediate the relationship between peer relationship functions and the job attitudes of job satisfaction, organizational commitment, intentions to leave the organization, role stress, and job burnout.

The provision of vocational and psychosocial support by a peer developmental relationship may also contribute to more positive work experiences (Kram \& Isabella, 1985; Siegel et al., 1998). The information sharing, career strategizing, job-related feedback, personal feedback, emotional support and friendship that occurs in a developmental peer relationship may positively influence job satisfaction and organizational commitment in that they promote feelings of acceptance, belonging, security and personal and career growth in the employee. In addition, accountants who have strong ties with peers may be less likely to leave the CPA firm. This may be especially true if the support of a special peer was instrumental in enhancing the job performance of the accountant. Similarly, a close peer relationship could help reduce role stress and job burnout. Having a close peer relationship, with the concomitant exchanges of information and mutual support, may make it easier for an employee to discern what is expected of him/her, as well as enable him/her to garner tips on how to deal with potentially difficult and contradictory demands for his/her efforts made by others in the organization. Job burnout may be diminished since having a rewarding interpersonal relationship may diminish the levels of fatigue, apathy, and the like that the employee experiences as he/she contemplates going to work.

Finally, it is well known that many businesses, especially CPA firms, rely heavily on temporary and permanent project teams to carry out many activities (e.g., Sutton and Hayne, 1997; also see Kleinman and Palmon, 2000; Kleinman, Palmon and Lee, 2002). Thus the level of the employee's orientation toward teamwork is important in that being positively disposed toward working in teams should foster the employee's devotion of energy toward the success of the same. Having close developmental peer relationships, therefore, should make working in teams more rewarding for the employee in that such teamwork gives him/her more opportunities to engage in activities with the valued peer(s) (e.g., Kleinman, Palmon \& Lee, 1999).

\footnotetext{
${ }^{2}$ Employees who were with the firm for a maximum period of six months.
} 
Hence, the following hypotheses are proposed:

$\mathbf{H}_{1}$ : $\quad$ Peer functions are significantly related to attitudinal outcomes.

$\mathbf{H}_{\mathbf{1}}(\mathbf{a})$ : Vocational and psychosocial peer functions are positively related to job satisfaction, organizational commitment, and teamwork orientation.

$\mathbf{H}_{1}$ (b): Vocational and psychosocial peer functions are negatively related to intentions to leave, role stress and job burnout.

The literature review indicated that peer relationships were linked to socialization content (e.g., performance proficiency, people, language, organizational goals and values, politics, and history) and information acquisition (about the task, role, group and organization) (Allen et al 1995; Ostroff \& Kozlowski, 1993; Siegel et al., 1998; Siegel, 2000). Organizational socialization is defined as the process by which an individual comes to appreciate the values, abilities, expected behaviors, and social knowledge essential for assuming an organizational role and for participating as an organizational member (Blank et al., 1991). Socialization is viewed as a learning process (Chao, Kozlowski, Major \& Gardner, 1994). It has also been suggested in the literature that peer relationships provide an opportunity for personal learning. Accountants involved in this learning forum (peer relationships) can develop skills (communication, active listening, persuasion, organizational skills), a sense of how their actions affect others, and how they are perceived in the organization (Kram \& Hall, 1995; Savage, 1990; Senge. 1990). Accordingly, the following hypotheses are proposed:

$\mathbf{H}_{2}$ : Peer developmental functions are significantly related to socialization and personal learning.

$\mathbf{H}_{2}$ (a): Vocational and psychosocial peer functions are positively related to socialization content (history, language, politics, people, organizational goals and values, and performance proficiency).

$\mathbf{H}_{2}$ (b): Vocational and psychosocial peer functions are positively related to personal learning (job context and skill development).

Socialization has been linked to attitudinal outcomes such as job satisfaction, organizational commitment, and turnover intentions (Chao et al. 1994; Blank et al., 1991). Personal learning is a very new concept, as applied to public accounting research. To date empirical research on forms of learning has been limited to issues of socialization and attitudinal outcomes. The more information, skills and knowledge an employee acquires, the more they can contribute to their job, work group and firm. Learning also serves to improve a person's self-efficacy and confidence. It can be anticipated, therefore, that accountants who are experiencing learning in their organizations will have more positive feelings about their work, will have greater information available to them to help them deal with role-related problems at work, and will have greater intellectual resources available to them about their work, helping diminish the perceived burden of performing that work.

Hence, it is hypothesized that:

$\mathbf{H}_{3}$ : $\quad$ Socialization will be significantly related to attitudinal outcomes.

$\mathbf{H}_{3}$ (a): Socialization will be positively related to job satisfaction, organizational commitment and teamwork orientation.

$\mathbf{H}_{3}$ (b): Socialization is negatively related to intentions to leave, role stress, and job burnout.

$\mathbf{H}_{4}$ : $\quad$ Personal learning is significantly related to attitudinal outcomes.

$\mathbf{H}_{4}$ (a): Personal learning is positively related to job satisfaction, organizational commitment and teamwork orientation.

$\mathbf{H}_{\mathbf{4}}$ (b): Personal learning is negatively related to intentions to leave, role stress, and job burnout.

\section{The Mediator Hypothesis}

The mediator hypothesis proposed earlier is illustrated in Figure 1. As noted above, the model suggests that learning, in the form of organizational socialization and personal learning, mediate the relationship between peer relationship functions and the job attitudes of job satisfaction, organizational commitment, intentions to leave the organization, role stress, and job burnout. Understanding whether the relationship between peer relationship functions and job attitudes is independent of, or is partially or wholly mediated by, organizational socialization and 
personal learning is important. It is important because such information allows us to understand more clearly the context within which job attitudes are formed. That is, should peer relationship functions operate independently of the two learning variables, organizational socialization and personal learning, then we can understand that peer relationships can affect job attitudes whether or not the individual is gaining knowledge about his/her work environment or perceives him/herself as gaining new skills. If organizational socialization and personal learning mediate the effects of peer relationship functions on job attitudes, then it is clear that the various mechanisms of socialization and methods used to foster learning must be present and effective in order for peer relationships to have an effect. The import of a finding that organizational socialization and personal learning affect job attitudes but that peer relationship functions do not is that managers and educators need not be concerned about peer relationship functions in determining how to foster more positive job attitudes. Instead, managers and educators interested in learning in the workplace can pay more attention to how to foster organizational socialization and personal learning. The mediator hypothesis, therefore, ties together the several strands of this study and enables us to discern which construct(s) (personal learning, organizational socialization, and/or peer relationship functions) promote more positive job attitudes.

The mediator hypothesis is:

H5: The relationship between peer relationships and attitudinal outcomes will be mediated by socialization and personal learning.

\section{Section IV}

Research Design

The data were collected by the researchers, on site, from twelve offices of national CPA firms. These offices were located in the Southeastern, Northeastern and Southwestern sections of the United States. The human resource managers of each office assisted the researchers in randomly selecting 612 accounting professionals for participation in this study. These subjects were randomly selected. Due to time commitments and scheduling, 440 professionals participated, giving a response rate of $72 \%$. The random selection process underlies the assumption that the sample did not differ from the organizational population in terms of age and gender. Three hundred respondents were male and 140 were female. The mean age of the respondents was 36.7 with a mean tenure of 8.2 years in the CPA profession.

\section{Measures}

This section describes the selection and creation of items used in the survey instrument. Final scale properties are shown in Table 1.

Peer Relationship Functions: A new measure was created to assess peer developmental relationships based on Kram and Isabella's (1985) qualitative findings. The content domain articulated by Kram \& Isabella (1985) included information sharing, career strategizing, job-related feedback, confirmation, emotional support and personal feedback. Seventeen items were written and content adequacy was assessed using procedures outlined by Schriesheim et al. (1993). Eighty-three (83) undergraduate and MBA students were used to make theoretical judgments about each item's content. The definitions employed for the vocational and psychosocial dimensions of peer relationships were derived from Kram and Isabella (1985). The undergraduate and MBA students were used to make theoretical judgments about each item's content.

Peer Relationship Functions. A new measure was created based on Kram \& Isabella's qualitative findings (1985) to assess peer developmental relationships. Content domain articulated by Kram \& Isabella (1985) included information sharing, career strategizing, job-related feedback, confirmation, emotional support and personal feedback. Seventeen items were written and content adequacy was assessed using procedures outlined by Schriesheim a al. (1993); 83 undergraduate and MBA students were used to make theoretical judgments about each item's content, and the definitions which were employed for the vocational and psychosocial dimensions of peer relationships were derived from Kram and Isabella (1985). Peer relationship items were tested with additional items 
created for the personal learning scale to see if they were distinct scales.

We factor analyzed, using a principal axis factor analysis procedure with a varimax rotation, the ratings of the preliminary participants. The factor solution was determined using the criteria of eigenvalues $>1.0$, the scree test and the interpretability of factors (Gorsuch, 1983). Loadings of .40 or higher were considered significant as suggested by Ford, MacCallumn \& Tait (1986).

Because we have two sets of items that may overlap, the peer relationship items and the personal learning items, we conducted a factor analysis of the combined set of items. The two sets of items did not overlap in practice. The peer relationship items loaded on two factors. The personal learning items loaded on a third factor, with two items also loading on a peer relationship factor. The treatment of the double-loaded items is presented in the Personal Learning section of this paper. With respect to the peer relationship items, the factor analysis revealed two underlying dimensions: a vocational dimension and a psychosocial dimension. Due to space constraints on the survey instrument, the 12 highest loading items were selected to represent the peer relationship functions: seven items for the vocational dimension, and five for the psychosocial dimension.

The respondents were asked to indicate their level of agreement with each of the 12 items about their special peer relationships. ${ }^{3}$ The Likert response scale ranged from "Strongly Disagree" (scored as 1) to Strongly Agree" (scored as 5). To test the two-factor model, a confirmatory factor analysis (CFA) was conducted on the survey sample respondent data pertaining to peer relationships. The proposed two-factor model adequately fit the survey sample data (Goodness of Fit Index $(\mathrm{GFI})=.85$, Comparative Fit Index $(\mathrm{CFI})=.89$. Non-Normed Fit Index $(\mathrm{NNFI})=.87)$. A one-factor model was also tested. The Chi-Square was higher for the one-factor model and showed a decrease in all fit indices. Cronbach alpha reliability estimates were .90 for the seven-item vocational scale and .90 for the five-item psychosocial support scale.

Organizational Socialization: Chao, O’Leary-Kelly, Wolf, Klein \& Gardner's (1994) 34-item measure of organizational socialization was utilized to assess the amount of information learned about the organization. The authors of the measure report a six-factor structure consisting of history, language, politics, people, organizational goals and values, and performance proficiency factors.

Confirmatory factor analysis was conducted to verify the measure's factor structure. Chao et al.'s (1994) six-factor model did not fit the data well $(\mathrm{GFI}=.79, \mathrm{CFI}=.75, \mathrm{NNFI}=.73)$, also internal reliability estimates were quite low for four of the six scales $(.75, .67, .66, .68, .82$ and .68 , respectively). Therefore, exploratory factor analysis was conducted on the data to elucidate the underlying factor structure here. An unconstrained rotated factor solution resulted in seven factors.

The factor analysis showed scales interpretable as follows: a designated politics scale (4 items), a designated history scale (3 items), an organizational goals and values scale (5 items), a people scale (6 items), a performance proficiency scale ( 3 items). The other factors were difficult to interpret. The Cronbach alpha reliabilities for the four factors were $.80, .82, .67$ and .66 for the politics/history, organizational goals and values, people, and performance proficiency scales respectively. The two factors, politics/history scale (referred to hereafter as politics) and the organizational goals and values scale (referred to hereafter as organizational goals) were utilized since only these scales demonstrated adequate reliability (i.e., a Cronbach alpha greater than .70) (Cf., Nunnally, 1978).

Personal Learning: Based on the results of the qualitative study, a measure was created to assess what individuals learn from their developmental relationships. Twelve items were written and content adequacy was assessed using procedures outlined by Schriesheim et al. (1993). As noted above, the personal learning items were tested with the peer relationship items and found to be distinct. Personal learning was defined as "acquisition of knowledge or skill that contributes to the development of an individual." All twelve items loaded on one factor representing the underlying single dimension of personal learning. All 12 items were included in the personal learning scale instrument since loadings on the a priori hypothesized factor were greater than .70. Higher scores

\footnotetext{
${ }^{3}$ Defined as a relationship with a colleague. Specifically, someone in the same or approximate level in the CPA firm, whom the respondent feels supports his or her personal or professional growth .
} 
on the 5-point scale indicated greater agreement.

A confirmatory factor analysis on the one-factor model showed fit indices that were lower than the recommended $.90\left(\mathrm{X}^{2}=448.07 . \mathrm{df}=54, \mathrm{WI}=.80, \mathrm{CFI}=.77, \mathrm{NNFI}=.72\right)$. Exploratory factor analysis procedures were then used to examine the underlying factor structure. Results indicated two factors existed: a factor representing learning related to one's job context, and a factor representing skill development. Each had six items. The respective Cronbach alphas were .82 and .84 .

Job Satisfaction: The 20-item short version of the Minnesota Satisfaction Questionnaire (Weiss, Dawis, England, \& Lofquist, 1967) was utilized in this study. This measure is a global measure and includes items on intrinsic and extrinsic factors of job satisfaction. Respondents were asked how satisfied they were with specific aspects of their job and responded on a Likert-type scale that ranged from Strongly Disagree (scored 1) to Strongly Agree (scored 5). The coefficient alpha reliability was .90 for this sample. Although confirmatory factor analysis did not support the one-factor dimension $(\mathrm{GFI}=.77, \mathrm{CFI}=.72, \mathrm{NNFI}=.73)$, the measure was scored as a global measure due to the MSQ's demonstrated reliability and validity (Cook, Hepworth, Wall \& Warr, 1981).

Organizational Commitment: The 15-item Organizational Commitment Questionnaire (Mowday, Steers, \& Porter, 1979) was used and respondents indicated their level of agreement with the same Likert scale described above. Confirmatory factor analysis supported the one-factor dimension suggested by Mowday et al. (1979) (GFI $=.90, \mathrm{CFI}=.91, \mathrm{NNFI}=.90)$. Coefficient alpha reliability was .88 .

Intentions to Leave: Rosin and Korabik's (1991) 4-item Intention to Leave scale was employed in the survey instrument. Respondents were asked whether they (a) would leave, (b) were planning to leave, (c) were actively searching for a job, and (d) had ever had thoughts of leaving their job. Scores were summed over the items with the higher scores indicating greater intentions to leave the organization. Confirmatory Factor Analysis confirmed the one-factor model $(\mathrm{GFI}=.94, \mathrm{CFI}=.91, \mathrm{NNFI}=.90)$. Coefficient alpha equaled .75 .

Job Burnout: This attitude was measured by Form A of the Gillespie-Numerof Burnout Inventory (Gillespie \& Numerof, 1984). Survey participants indicated their level of agreement with ten statements on a scale ranging from 1 (Strongly Disagree) to 5 (Strongly Agree). Confirmatory factor analysis of the responses indicates the one-factor model of a global scale is supported $(\mathrm{GFI}=.84, \mathrm{CFI}=.92$, NNFI $=.92)$. Coefficient alpha reliability for the ten-item measure in this sample was .96.

Role Stress: This outcome was measured by the eight-item role conflict and six-item role ambiguity scales from Rizzo, House \& Lirtzman (1970). A one-factor one-dimensional model was not supported by confirmatory factor analysis $(\mathrm{GFI}=.83, \mathrm{CFI}=.73$. NNFI $=.68)$ but results from the two-factor model showed an adequate fit for the data $(\mathrm{GFI}=.90, \mathrm{CFI}=.86, \mathrm{NNFT}=.83)$. Thus, role conflict and role ambiguity will be examined separately in the current study. Cronbach alpha for the scales were $.81(\mathrm{~N}=416)$ and $.72(\mathrm{~N}=414)$ respectively.

\section{Data Analysis}

Hypotheses 1-4: Hierarchical multiple regression analyses were conducted to assess the contribution of the various dimensions of peer developmental relationships to each attitudinal response and learning measure, and the contribution of learning to each attitudinal response measure. The hierarchical technique permits the determination of the unique contribution of each set of variables to variation in the dependent variables. The following steps were taken to avoid confounding of results due to covariation of the demographic and developmental characteristics with the dependent and independent variables. First, demographic variables were entered as a block. Second, the durations of the special peer relationship and time spent with the peer per week were entered as a second block. In the last step, the independent variables of interest were entered (third block). At each step, the $\mathrm{R}$ ${ }^{2}$, the change in $\mathrm{R}^{2}$, the overall $\mathrm{F}$ value and the change in $\mathrm{F}$ values were examined for their significance.

Hypotheses 1, 2, 3 and 4 stated that the blocks of peer developmental functions (vocational and psycho- 
logical) or forms of learning would account for a significant incremental variance ${ }^{4}$ and that the regression weights for each developmental function or learning form will be significant in the hypothesized direction for each of the criterion response variables.

Hypotheses 5: LISREL 8 (Joreskog \& Sorebom, 1993) was used to test the mediation models proposed by hypothesis 5 via path analyses. This hypothesis sought to determine whether forms of learning mediate the relationship between peer functions and attitudinal outcomes. For mediation to exist, predictor variables have to be significantly related to the mediators, mediator variables have to be significantly related to the dependent variables, and there has to be a substantial reduction in the relationship between the predictor and dependent variables when the mediator is included (Baron \& Kenny. 1986). Complete mediation is evidenced by a non- significant relationship between predictor and dependent variables once the mediator is included. Paths were estimated by latent-variable structural modeling methods (Baron \& Kenny, 1986). The use of LISREL is preferred as a method of testing mediation because it accounts for measurement error, provides the decomposition of correlations among variables, and tests causality among the variables (James \& Brett, 1984: Joreskog \& Sorebom. 1993).

\section{Section V}

Results

Table 7 presents means, standard deviations and intercorrelations for the independent and dependent variables. Peer vocational support and peer psychosocial support for peer developmental relationships are highly intercorrelated $(\mathrm{r}=.74, \mathrm{p}<.01)$. Socialization of politics in the organization and personal learning about the job context have the highest inter-correlation among the various types of learning variables $(r=.61, p<.01)$, with the remainder of inter-correlations characterized as low to moderate. With respect to inter-correlations among the attitudinal outcome variables, job satisfaction and organizational commitment are strongly correlated. Moderate intercorrelations exist among the other outcome variables.

Hypothesis 1: Hypothesis 1 states that peer developmental functions would significantly affect attitudinal outcomes. More than half of the respondents $(65.7 \%)$ reported having a special peer relationship with someone in the organization. The average duration of this relationship was 30.6 months.

Table 2 summarizes the results of the hierarchical regression analyses for peer developmental functions and the attitudinal outcome variables. The demographic variables accounted for significant variance in job satisfaction $\left(\Delta \mathrm{R}^{2}=.066, \mathrm{p}<.05\right)$ and intentions to leave the organization $\left(\Delta \mathrm{R}^{2}=.082, \mathrm{n}<.01\right)$. Age was negatively related to intentions to leave the organization $(\beta=-.226, \mathrm{p}<.01)$ and race was positively associated with intentions to leave $(\beta=.147, \mathrm{p}<.05)$. Although the contribution of demographic variables to job burnout was marginally significant $\left(\Delta \mathrm{R}^{2}=.062, \mathrm{p}<.10\right)$, the regression weight for age was significant in the negative direction $(\beta=-192, \mathrm{p}$ c .01) indicating that as age increased, job burnout decreased. Age also was a significant predictor of organizational commitment $(\beta=.154, \mathrm{p}<.05)$ although the block of demographic variables did not contribute significantly to the variance in organizational commitment. The duration of the peer relationship and the amount of time spent with the peer each month did not explain significant variance in the attitudinal outcomes.

The addition of peer developmental functions in the third step resulted in a significant increment in explained variance for only one attitudinal outcome: role ambiguity $\left(\Delta \mathrm{R}^{2}=.045, \mathrm{p}<.01\right)$. Psychosocial support was negatively related to role ambiguity $(\beta=-.307, \mathrm{p}<.01)$. Contrary to expectations, vocational support was positively associated with role ambiguity $(\beta=.239, \mathrm{p}<.05)$. Peer functions did not contribute to variance in job satisfaction, organizational commitment, intentions to leave the organization, role conflict or job burnout. Thus, hypothesis 1 received limited support.

Hypothesis 2: Table 2 summarizes the results of the hierarchical regression analyses for the hypothesis that peer developmental functions will affect learning variables. Demographic variables accounted for significant

\footnotetext{
${ }^{4}$ Beyond that accounted for by the demographic variables and characteristics of the peer relationship entered in the regression equation.
} 
variance in socialization of organizational goals and values $\left(\Delta \mathrm{R}^{2}=.086, \mathrm{p}<.01\right)$. Age was positively related to this specific type of learning $(\beta=.216, \mathrm{p}<.01)$. Although demographic variables as a group did not account for significant variance in socialization of politics, personal learning of job context, or personal learning through skill development, tenure was positively related to socialization of politics $(\beta=.173, \mathrm{p}<.05)$ and age was negatively-related to skill development $(\beta=-.148, p<.05)$. Characteristics of the peer relationship accounted for significant incremental variance in personal learning through skill development $(\Delta \mathrm{R} 2=.030, \mathrm{p}<.05)$. Hours spent with the peer per month were positively associated with this type of learning. Characteristics of the peer relationship did not account for significant variance in socialization of organizational goals and values, socialization of organizational politics, or personal learning of job context. In addition, beta weights for the relationship characteristics were not significantly related to these types of learning in an organization.

The addition of developmental peer functions to the regression equations accounted for significant incremental variance for two of the four learning variables: Socialization of organizational goals and values $\left(\Delta R^{2}\right.$ $=.030, \mathrm{p}<.05)$ and personal learning through skill development $\left(\Delta \mathrm{R}^{2}=.043, \mathrm{p}<.01\right)$. However, the beta weights for vocational support and psychosocial support were not significant for socialization of organizational goals and values. Peer vocational support was positively related to personal learning through skill development $(\beta=.192, \mathrm{p}<$ .05). Peer psychosocial support was marginally related to personal learning of job context, with increased psychosocial support associated with increased personal learning of job context $(\beta=.182, \mathrm{p}<.10)$. Peer functions as a block of variables did not account for significant variance in socialization of organizational politics or personal learning of job context. Thus, hypothesis 2 received limited support.

Hypothesis 3: Consistent with hypotheses 3(a) and (b), organizational socialization accounted for significant incremental variance in all seven attitudinal outcomes. Percent of variance explained ranged from $10.5 \%$ in intentions to leave $(\mathrm{DF}=23.253, \mathrm{p}<.01)$ to $39.1 \%$ in organizational commitment $(\mathrm{DF}=125.035, \mathrm{p}<.01)$. Socialization of organizational goals and values represented the primary contributor to all attitudinal outcomes. Socialization of organizational politics was a significant secondary predictor of job satisfaction $(\beta=.156, p<.01)$, and role ambiguity $(\beta=-.157 . p<.01)$. Socialization of organizational politics was not a unique contributor to organizational commitment, intentions to leave, role conflict, and job burnout or teamwork orientation. See Table 2 for a summary.

Hypothesis 4: With respect to hypothesis 4, personal learning accounted for significant incremental variance in six of the seven-attitudinal outcomes ranging from $3.5 \%$ explained variance in intentions to leave the organization $(\mathrm{DF}=7.350, \mathrm{p}<.01)$ to $20.0 \%$ in job satisfaction $(\mathrm{DF}=47.230)$. Personal learning did not account for significant incremental variance in role conflict. Personal learning of job context was the principle contributor, and was related to six of seven attitudinal outcomes in the expected direction; it was not associated with role conflict. Personal learning through skill development significantly contributed to five of the seven-attitudinal outcomes. This type of learning was not related to intentions to leave the organization or role conflict. Thus, hypothesis 4 received support. See Table 2 for a summary.

Hypothesis 5: (Mediator Hypothesis) The hierarchical regression results indicated that peer developmental functions were related, in an unexpected direction, to only one attitudinal outcome (role ambiguity), and to only one aspect of personal learning. Thus, the requisite conditions for a mediation model were not met and the hypothesis was therefore not tested.

\section{Section VI}

\section{Conclusions}

Peer relationships as learning forums were examined in an attempt to measure their contribution to learning in an organization. The relationship between peer forums, individual learning, and employee attitudes was analyzed. Organizational socialization and personal learning were defined as indicators of learning. Important job attitudes such as job satisfaction, organizational commitment, intentions to leave, role ambiguity, role conflict, job burnout, and teamwork orientation were examined. 


\section{Learning Forums and Individual Attitudes}

Peer developmental functions, in general, did not affect the majority of attitudinal outcomes. Peer relationships that provide opportunities for sharing information, strategizing about careers, offering friendship and emotional support to one another, do not appear to increase either job satisfaction or commitment to the CPA firm. Neither do they decrease an accountant's intention to leave the firm, reduce role conflict or job burnout. This finding may be related to the fact that the firms were characterized by a high degree of internal change (e.g., merger activity). The results of our inquiry provide evidence that information sharing and vocational support of peers increased, rather than decreased, role ambiguity. We suggest that during periods of restructuring, contradictory information may be exchanged, thus leading to increased role ambiguity and tension.

\section{Learning Forums and Individual Learning:}

Peer developmental functions contributed to personal learning in terms of skill development. The advice, career strategizing and job-related feedback (vocational support) provided by a peer lead to an accountant's ability to communicate more effectively with others and develop new ideas and skills. Peer relationships did not contribute to greater knowledge of firm goals, values, or politics. Nor was there increased understanding of the impact that each individual's contribution had on fellow employees. In a changing, uncertain environment, peers may not be able, or trusted, to provide one another with reliable firm-related information.

\section{Learning Variables and Attitudinal Outcomes}

Socialization significantly influenced job attitudes. Socialization of organizational goals and values was the most important predictor of attitudes. Accountants who understand and identify with the firm's goals and values may be more likely to have a higher degree of job satisfaction, organizational commitment, and be less likely to leave the firm. In addition, accountants who learn and adopt the goals and values of the firm, appear to experience less role ambiguity, role conflict and job burnout. The socialization of politics influenced learning to a lesser degree than the socialization of goals and values. Politics was, however, significantly related to increased job satisfaction and less role ambiguity. Increased knowledge of the CPA's firm history, rituals, and power brokers, results in increased job satisfaction and a reduction of role ambiguity. Socialization was the most significant factor underlying (39.1\% of explained variance) commitment to the CPA firm.

The results provide significant support for the hypothesis that personal learning would significantly affect attitudinal outcomes. We found that personal learning significantly affected the job-related attitudes of accountants, with the sole exception of role conflict. Learning how their job affected others, and an increased understanding of how they were perceived in a firm, resulted in greater job satisfaction and organizational commitment. Further, intentions to leave, role ambiguity, and job burnout were reduced. Although skill development contributed to a more positive work experience, it did not reduce an accountant's intentions to leave the firm. Many factors (e.g., economic considerations and expected career mobility) other than whether a person learns new skills can determine whether someone is interested in staying with the firm (Scandura \& Viator, 1994). Personal learning was the most significant contributing factor to job satisfaction (20\% of explained variance).

\section{Limitations of our Inquiry}

The results of our inquiry are based on a questionnaire utilizing self-report measures. This design raises the possibility that common source method variance ${ }^{5}$ may contribute to the results. Attitudinal variables require assessing the perceptions of the employees. Future research may consider a comparative analysis using the responses of peers or supervisors. It would be of interest to compare and contrast their perceptions of acquired knowledge and socialization. Another limitation relates to omitted variables. In addition to socialization with respect to politics/history and organizational goals and values, the socialization scale designed by Chao et al. (1994) assesses socialization with respect to people, language and performance proficiency. Measurement issues precluded including these variables in our study. Nonetheless, inclusion of the above in future research may provide insight in-

\footnotetext{
${ }^{5}$ Meta-analysis has demonstrated that method variance is not as significant of a problem as has been typically assumed (Major et al., 1995).
} 
to how CPA's learn the terminology and jargon that is specific to CPA firms, and obtain information on their performance proficiency.

\section{Implications for Practice}

In order for firms to become learning organizations, organizations have to provide appropriate forums within which learning can take place. The results of our research provide evidence that peer relationships provide an appropriate forum within which learning can take place. Firms should encourage the formation of peer relationships and design activities that will promote these relationships. Providing each employee access to a peer who will share information regarding organizational goals, values, and politics, will greatly enhance the firm's ability to become a learning organization.

This study found that vocational support provided by a peer in terms of career strategizing, exchanging ideas about how to handle work-related issues and job-related feedback contributed to the skill development of the employees. However, vocational support from a peer also increased role ambiguity. The degree of change and turbulence within an organization is an important contextual factor to consider when examining peer relationships. Further research needs to be conducted in other types of organizations to elucidate the conditions under which peer developmental relationships contribute to learning and job outcomes. Organizations that are experiencing restructuring and downsizing create environments in which distrust and competition flourish. Employees are concerned with their own job security, thus sharing information may not be in their own interest. Additional qualitative and empirical work is needed to increase our understanding of how and when peer relationships contribute to an individual's personal and professional development.

\section{References}

1. Allen, T. D., Maetzke, S. B. \& Russell, J. E. (1994). Formal Peer Mentoring: Factors Related to Protégé's Satisfaction and Willingness to Mentor Others. Paper presented at the Southern Management Association Meeting, New Orleans, LA.

2. Allen, T. D., McManus, S. E., Russell, J. E. \& Reiniger, A. (1995). An Examination of the Impact of Peer Mentoring on Socialization and Stress. Paper presented at the Southern Management Association Meeting, Orlando, FL.

3. Baron. R. M. \& Kenny, D. A. (1986). The Moderator-Mediator Variable Distinction In Social Psychology Research: Conceptual, Strategic, And Statistical Considerations. Journal of Personality and Social Psychology, 5, 1173-1182.

4. Bennett, J. K. \& O’Brien, M. J. (1994). The Building Blocks Of The Learning Organization. Training, 31: 41-49.

5. Blank, M., Siegel, P., and Rigsby, J. (1991) Determinants of International CPA Firm Orientation Among Accounting Students. British Accounting Review, 23: 281-300.

6. Chao, O. T., Kozlowski, S. W., Major, D. A. \& Gardner, P. (1994). The Effects Of Organizational Tactics And Contextual Factors On Newcomer Socialization And Learning Outcomes. Paper presented at the Society for Industrial and Organizational Psychology Meeting, Nashville, TN.

7. Chao, O. T., O’Leary-Kelly, A. M., Wolf, S., Klein, H. J. \& Gardner, P. D. (1994). Organizational Socialization: Its Content And Consequences. Journal of Applied Psychology 79, 730-743.

8. Clawson, J. G. (1996). Mentoring In The New Information Age. Special issue of The Leadership \& Organizational Development Journal, 'Developing the Leaders of Tomorrow through Mentoring," 12. 6-15.

9. Cook, J., Hepworth, S., Wall, T. \& Warr, P. (1981). The Experience of Work. New York: Academic Press.

10. Dodgson, M. (1993). Organizational Learning: A Review Of Some Literatures. Organization Studies, 14: 375-394.

11. Dreher, G. F. \& Ash, R. A. (1990). A Comparative Study Of Mentoring Among Men And Women In Managerial, Professional And Technical Positions. Journal of Applied Psychology, 75, 539-546.

12. Fagenson, E. A. (1989). The mentor advantage: Perceived career/job experiences of protégés vs. nonprotégés. Journal of Organizational Behavior, 10:309-320.

13. Ford, J. K., MacCallum, R. C. \& Tait, M. (1986). The Application Of Exploratory Factor Analysis In Ap- 
plied Psychology: A Critical Review And Analysis. Personnel Psychology, 39: 291-314.

14. Gillespie, D. \& Numerof, R. (1984). The Gillespie-Number of Burnout Inventory: Technical Manual. Washington University, St. Louis, Missouri.

15. Gorsuch, R. L. (1983). Factor Analysis, 2nd Ed. Hillsdale, NJ: Erlbaum.

16. Habler, B. \& Lowe, R. (1985). The Mentoring Relationship In Organizations. Proceedings of the Southeastern Organizational Development Group, 26-31.

17. Hunt, D. M. \& Michael, C. (1983). Mentorship: A Career Training And Development Tool. Academy of Management Review, 8: 475-485.

18. James, L. R. \& Brett, J.M. (1984). Mediators, Moderators, And Tests For Mediation. Journal of Applied Psychology, 69: 307-321.

19. Joreskog, K. G. \& Sorebom, D. (1993). LISREL 8: Structural Equation Modeling with the SIMPLIS Command Language, Scientific Software International.

20. Kaplan, S.E., Keinath, A. K., and Walo, J. C. (2001). An Examination Of Perceived Barriers To Mentoring In Public Accounting. Behavioral Research in Accounting, 13: 195-220.

21. Kleinman, G. and Palmon, D. (2001). Understanding Auditor-Client Relationships: A Multi-faceted Analysis. Princeton, NJ: Markus Weiner Publications.

22. Kleinman, G. and Palmon, D. (2000). The Auditor-Client Negotiation Game and Instructor's Notes. Journal of Accounting Case Research, 5(2).

23. Kleinman, G., Palmon, D. and Lee, P. (1999). An Analysis of the Dynamic Interplay Between Personal and Group Level Factors in an Auditor Independence Challenge Decision-Making Game. Presented at the Mid-Year Auditing Conference of the American Accounting Association, Atlanta, GA., on January $15^{\text {th }}, 1999$.

24. Kleinman, G., Palmon, D. and Lee, P. (2002 forthcoming). The Effect of Personal and Group Level Factors on the Outcomes of Simulated Auditor and Client Teams. Forthcoming in Group Decisions and Negotiations.

25. Kleinman, G., Siegel, P., and Eckstein, C. (2002 forthcoming). Teams As A Learning Forum For Accounting Professionals. Forthcoming in the Journal of Management Development, vol. 21.

26. Kleinman, G., Siegel, P., and Eckstein, C. (2001). Mentoring and Learning: The Case of CPA Firms. Leadership and Organizational Development Journal, 2001, 22(1): 22-34.

27. Kram, K. E. \& Hall, D. T. (1995). Mentoring In A Context Of Diversity And Turbulence. In S. Label \& E. Kossek (Eds.) Human Resource Strategies for Managing Diversity, London: Blackwell Publishers.

28. Kram, K. E. \& Isabella, L. A. (1985). Mentoring Alternatives: The Role Of Peer Relationships In Career Development. Academy of Management Journal, 28: 110- 132.

29. Kram, K. E. (1983). Phases Of The Mentor Relationship. Academy of Management Journal, 26: 608625.

30. Kram, K. E. (1985). Mentoring at Work: Developmental Relationships in Organizational Life. Glenview, IL: Scott, Foresman and Company.

31. McKnight, D. H., Cummings, L. L. and Chervany, N. L. (1998). Initial Trust Formation In New Organizational Relationships. Academy of Management Review, 23(3): 473-490.

32. Mowday, R. T., Steers, R. M., \& Porter, L. W. (1979). The Measurement Of Organizational Commitment. Journal of Vocational Behavior, 14: 244-247.

33. Noe, R. A. (1988). An Investigation Of The Determinants Of Successful Assigned Mentoring Relationships. Personnel Psychology, 41: 457-479.

34. Nunnally, J. (1978). Psychometric Theory, 2d ed. NY: McGraw-Hill.

35. Ostroff, C. \& Kozlowski, S. (1993). The Role Of Mentoring In The Information Gathering Processes Of Newcomers During Early Organizational Socialization. Journal of Vocational Behavior, 42. 170-183.

36. Rizzo, J. R., House, R. 1. \& Lirtzman, S. I. (1970). Role Conflict And Role Ambiguity In Complex Organizations. Administrative Science Quarterly, 150-163.

37. Rosin, H. Id. \& Korabik, K. (1991). Workplace Variables, Affective Responses, And Intention To Leave Among Women Managers. Journal of Occupational Psychology, 64 317-330.

38. Savage, C. Id. (1990). Fifth Generation Management: Integrating Enterprises through Human Networking. San Francisco: Digital Press.

39. Scandura, T. A. (1992). Mentorship And Career Mobility: An Empirical Investigation. Journal of Organizational Behavior, 13, 169-174. 
40. Scandura, T. A. \& Viator, R. (1994). Mentoring In Public Accounting Firms: An Analysis Of MentorProtégé Relationships, Mentorship Functions, And Protégé Turnover Intentions. Accounting, Organizations \& Society 19 717-734.

41. Schriesheim, C. A., Powers, K. J., Scandura, T. A., Gardiner, C. C. \& Lankau, M. J. (1993). Improving Construct Measurement In Management Research: Comments And A Quantitative Approach For Assessing The Theoretical Content Adequacy Of Paper-And-Pencil Survey-Type Instruments. Journal of Management, 19: 385-417.

42. Senge, P. M. (1990). The Fifth Discipline: The Art and Practice of the Learning Organization. New York: Doubleday Currency.

43. Shaw, R. B. \& Perkins, D. N. (1991). Teaching Organizations To Learn. Organization Development Journal, 9: 1-12.

44. Siegel, P. H. (2000). Using Peer Mentors During Periods Of Uncertainty. The Leadership and Organization Development Journal, 21 (5/6): 243-253.

45. Siegel, P. H., Reinstein, A, Karim, K, and Rigsby, J. (1998). The Role of Peer Relationships During CPA Firm Mergers, Behavioral Research In Accounting, Vol. 10 (S), pp. 270-277.

46. Sutton, S. G. and S. C. Hayne. (1997). Chapter 4: Judgment and Decision Making, Part III: Group Processes. Edited by V. Arnold and S. G. Sutton, Behavioral Accounting Research: Foundations and Frontiers. Sarasota, FL: American Accounting Association.

47. Viator, R. E. (1999). An Analysis of Formal Mentoring Programs and Perceived Barriers to Obtaining a Mentor in Large Public Accounting Firms. Accounting Horizons, 13(1): 37-53.

48. Weiss, D. J., Dawis, R. V., England, G. W., \& Lofquist, L. H. (1967). Manual for the Minnesota Satisfaction Questionnaire, University of Minnesota.

49. Wilson, J. A. \& Elman, N. S. (1990). Organizational Benefits Of Mentoring. Academy of Management Executive, 4, 88-94. 
Figure 1 : Proposed Mediational Model for Peer Relationships

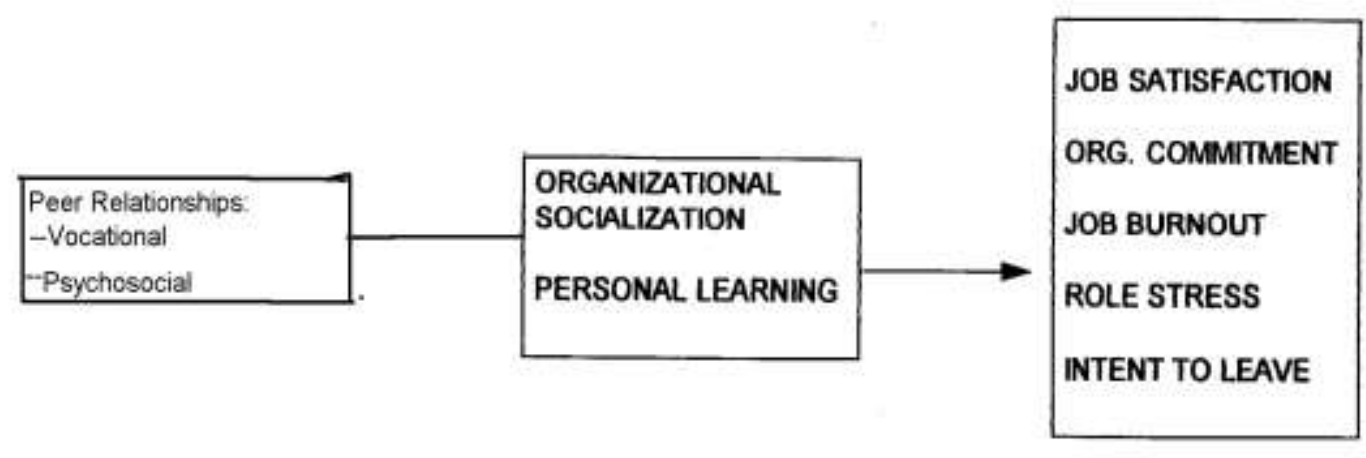

Please contact lead author for copies of the tables. 
